\title{
Photoelectrochemical Behavior of Some Methylium Salts Having Methoxyphenyl Groups at an ITO Electrode in 1,2-dichloroethane
}

\author{
Tatsuo ERABI, * Takayuki OHTSUKI, Eiko OSAKI, Yohko ISHIKAWA, \\ Tomomitsu NAGAREO, Masahiro ASAHARA, and Masanori WADA
}

\begin{abstract}
Department of Materials Science, Faculty of Engineering, Tottori University (4-101, Koyama-Minami, Tottori 680-8552, Japan)
\end{abstract}

\author{
Received November 15, 2001 ; Accepted February 12, 2002
}

\begin{abstract}
Photoelectrochemical behavior of triarylmethylium salts $\left(\left[\Phi_{3} \mathrm{C}\right] \mathrm{ClO}_{4}\right.$ and $\left[\Phi^{\prime} \Phi^{\mathrm{b}_{2}} \mathrm{C}\right] \mathrm{ClO}_{4}\left[\Phi\right.$ and $\Phi^{\prime}$ represent $2,4,6-$ trimethoxyphenyl, 2,6-dimethoxyphenyl, 2-methoxyphenyl, 4-methoxyphenyl, and phenyl groups]), expected as a novel photosensitizer, was studied at an ITO electrode in 1,2-dichloroethane under potentiostatic conditions. The slow increase in a cathodic current was observed upon illumination. The observed photocurrent depended on the applied potential, and the half-wave potential was close to the redox potential based on methylium-methyl radical redox couples. The photocurrent also depended on the concentration of the salts, and the illuminance of the incident light.
\end{abstract}

Key Words : Triarylmethylium Salts, Photogalvanic Cell, Photosensitizer

\section{Introduction}

The primary process of plant photosynthesis consists of several electron transport components. In the PS I reaction center of higher plants, the light induces the charge separation between the donor chlorophyll $a$ dimer, $\mathrm{P} 700$, and the acceptor chlorophyll $a$ monomer, Ao. It is followed by the sequential charge shift reactions from $\mathrm{A}_{0}{ }^{-}$to phylloquinone, $\mathrm{Q}$, and finally to $4 \mathrm{Fe}-4 \mathrm{~S}$ clusters, $\mathrm{Fx}, \mathrm{Fb}$, and $\mathrm{Fa}$. We have ever tried the extraction of this phylloquinone, $\mathrm{Q}$, and reconstitution of several artificial quinones into this Q-site. Then, we have measured the electron transfer rate from $\mathrm{A}_{0}{ }^{-}$to $\mathrm{Q}^{1}{ }^{1 \text { ) According to }}$ the Marcus theory, the electron transfer rate depends on free energy difference of the reaction of interest. When $\mathrm{Q}$ was replaced by different compounds, the $\mathrm{k}$ value significantly decreased in both the small and large $\Delta G^{0}$ regions, as expected. In addition, the native reaction center complexes seem to arrange reaction partners to obtain the maximal reaction rate. The data tell us that distance between redox centers, difference in redox potentials, and the relative orientation are strictly defined to achieve the conversion of solar energy with high quantum efficiency. That is, it is very important to control the redox potential of some redox components over the wide range in the construction of the multiple electron transfer system.

During the course of our study on 2,6-dimethoxyphenyl derivatives, we have attempted the synthesis of di- and triarylmethylium salts having some methoxy substituents on the phenyl group. ${ }^{2)}$ We found that the number and position of methoxy substituents on phenyl group influence remarkably on the stability and reactivity of these compounds. For example, bis(2,4,6-trimethoxyphenyl)methylium perchlorate is recrystallizable even from methanol, and triarylmethanols bearing at least four ortho-methoxy groups are highly basic to form isolable triarylmethylium salts even in secondary alcohols and water. In addition, we have recently reported ${ }^{3,4}$ ) the preparation and sorne phisicochemical properties of aryl (ferrocenyl)methanes and -methanols, and aryl(ferrocenyl)methylium and triarylmethylium salts. The wide range of cathodic shift in the redox potentials based on ferrocene-ferrocenium, and methylium-methyl radical redox couples could be observed as the number of orthoand para-methoxy groups increased. Furthermore, these methylium salts are highly colored, and characteristic absorption bands are observed in the visible spectrum. So, it is worth to report here the photoelectrochemical behavior of these methylium salts having a number of the excellent characteristics, such as water solubility and stability, large absorbance in the visible region, reversible one-electron redox behavior, and easily controllable redox potentials. Moreover, it seems valuable for the design of the novel photosensitizing system in so-called Graetzel-type photogalvanic cell. ${ }^{5}$ ) We will abbreviate here some methoxyphenyl groups as $\Phi$ 's, as shown in Scheme 1.

\section{Experimental}

Triarylmethylium salts $\left(\left[\Phi_{3} \mathrm{C}\right] \mathrm{ClO}_{4}\right.$ and $\left[\Phi^{\prime} \Phi^{\mathrm{b}}{ }_{2} \mathrm{C}\right] \mathrm{ClO}_{4}$ $\left.\left[\Phi, \Phi^{\prime}=\Phi^{\mathrm{a}}, \Phi^{\mathrm{b}}, \Phi^{\mathrm{e}}, \Phi^{\mathrm{f}}, \mathrm{Ph}\right]\right)$, were prepared as described
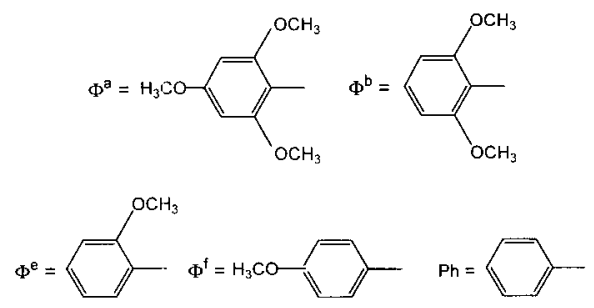

Scheme 1 
elsewhere, ${ }^{2,3)}$ and were checked by IR, ${ }^{1} \mathrm{H}$ - and ${ }^{13} \mathrm{C}$ NMR. These compounds were dissolved in 1,2-dichloroethane containing $0.1 \mathrm{M}\left(\mathrm{M}=\mathrm{mol} \mathrm{dm}^{-3}\right)$ tetrabutylammonium perchlorate. Dissolved oxygen in these solutions was removed by bubbling argon for $20 \mathrm{~min}$ before electrolysis. Photoelectrochemical measurements were carried out at an indium tin oxide (ITO) $\left(\mathrm{R}=10 \Omega \mathrm{cm}^{-2}\right)$ working electrode in an electrolytic cell under potentiostatic conditions. The surface area of this electrode was $3 \times 3 \mathrm{~cm}^{2}$. Photocurrents were measured upon illumination after polarization of the electrode in the dark at a certain potential. The light source was a $60 \mathrm{~W}$ tungsten lamp, usually using in combination with a Y-46 cut-off filter and a $12-\mathrm{cm}$ thick water filter in order to eliminate an excitation of ITO itself and thermal effects, respectively.

\section{Results and Discussion}

A typical current-time profile for $\Phi_{3}^{\mathrm{b}} \mathrm{C}^{+}$is shown in Fig. 1. The slow increase in cathodic currents following 0 $\sim 16 \mathrm{~s}$ of induction period was observed after illumination by all salts tested $\left[\boldsymbol{\Phi}^{\mathrm{a}} \mathrm{C}^{+}, \Phi^{\mathrm{b}} \mathrm{C}^{+}, \Phi^{\mathrm{e}} \Phi^{\mathrm{b}}{ }_{2} \mathrm{C}^{+}, \Phi^{\mathrm{f}} \Phi^{\mathrm{b}}{ }_{2} \mathrm{C}^{+}\right.$, and $\mathrm{Ph} \Phi^{\mathrm{b}}{ }_{2} \mathrm{C}^{+}$] under cathodic polarization. And the photocurrents reached a steady state $1 \sim 3$ min after illuminating. When the light was put off, the currents decreased gradually following $2 \sim 15 \mathrm{~s}$ of induction period, finally to the background. The increase in the cathodic currents upon illumination was defined as the magnitude of the photocurrents.

The observed photocurrents by all of triarylmethylium salts depended on the applied potential. As a typical example, the cathodic photocurrents by $\Phi_{3}^{\mathrm{b}} \mathrm{C}^{+}$were observed in the region more cathodic than $+100 \mathrm{mV}$ vs. aq. $\mathrm{Ag} / \mathrm{AgCl}$. The magnitude of the cathodic photocurrents increased with increasing cathodic shifts up to $-200 \mathrm{mV}$, and reached a plateau. (Fig. 2) The half-wave potential of the photocurrent-applied potential curve for $\Phi^{\mathrm{b}}{ }_{3} \mathrm{C}^{+}$was estimated to be $+5 \mathrm{mV}$, which was very close to the redox potential of $\Phi^{\mathrm{b}}{ }_{3} \mathrm{C}^{+}(+14 \mathrm{mV}$ vs. aq. $\mathrm{Ag} / \mathrm{AgCl}) .{ }^{4)} \mathrm{The}$

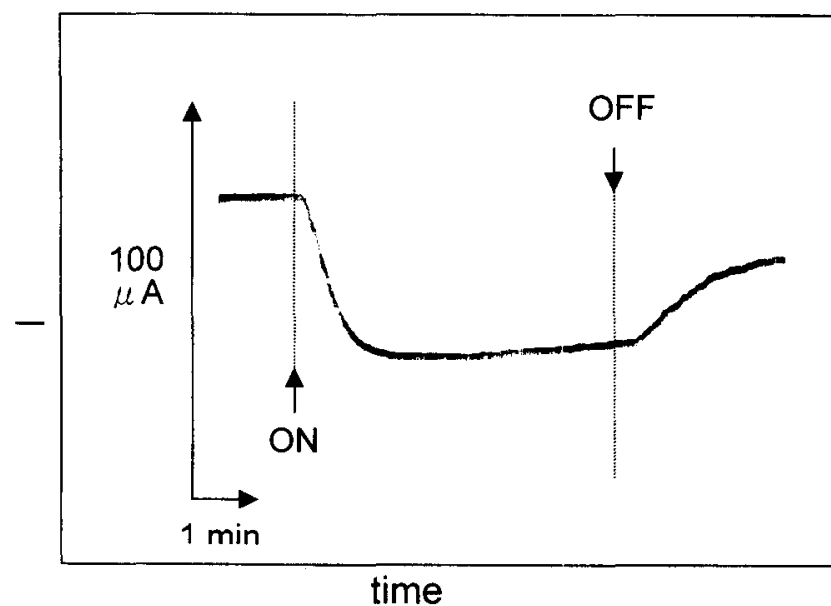

Fig. 1 Typical current-time profiles for the photocurrent generation by $\Phi^{\mathrm{b}} \mathrm{C}^{+}$. The current was measured at $-500 \mathrm{mV}$ vs. aq. $\mathrm{Ag} / \mathrm{AgCl}$ of applied potential, $6,000 \mathrm{~lx}$ of illuminance, and $0.5 \mathrm{mM}$ of $\Phi^{\mathrm{b}_{3} \mathrm{C}^{+}}$in 1,2-dichloroethane containing $0.1 \mathrm{M}$ tetrabutylammonium perchlorate. The surface area of the ITO electrode was $3 \times 3 \mathrm{~cm}^{2}$.

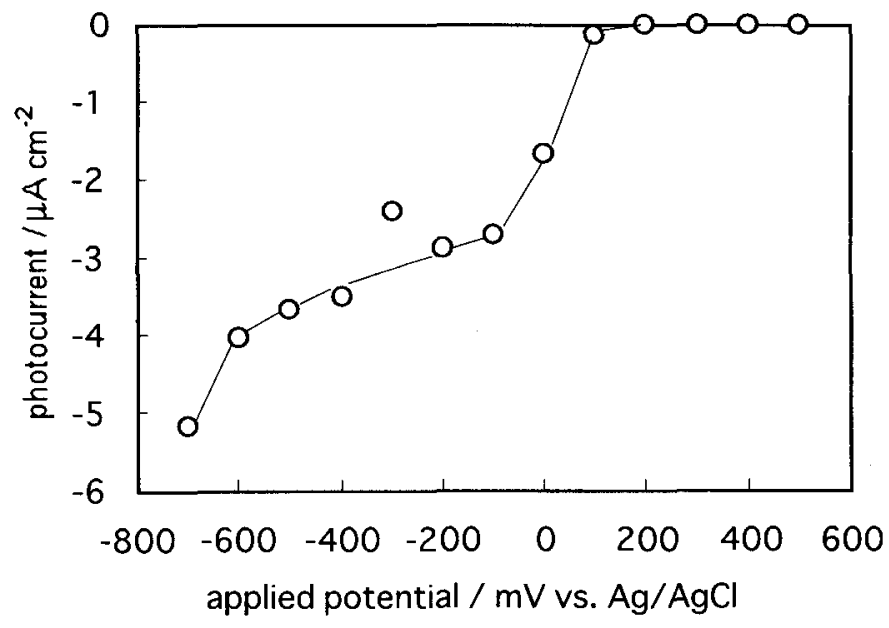

Fig. 2 Dependence of photocurrent by $\Phi^{b_{3} C^{+}}$on applied potential. The experimental conditions were the same as those in Fig. 1, except that the applied potential was varied.
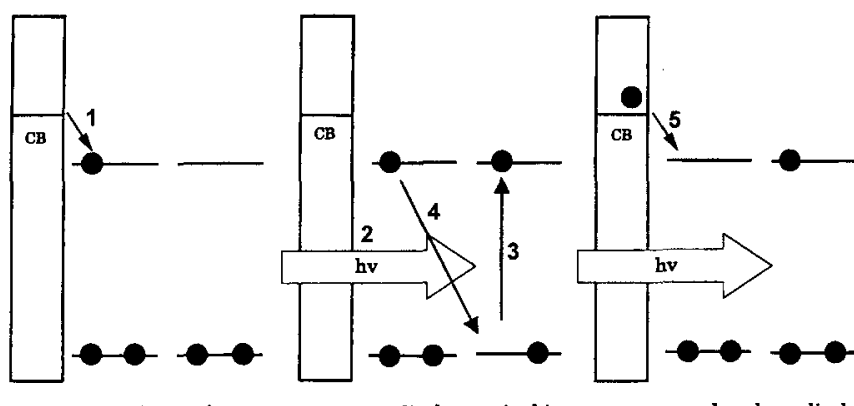

radical ion

radical excited ion ion

Fig. 3 A plausible mechanism for generation of photocurrent by $\Phi_{3} \mathrm{C}^{+}$or $\Phi^{\prime} \Phi^{\mathrm{b}}{ }_{2} \mathrm{C}^{+}$. First, the radical was accumulated at the electrode surface during the cathodic polarization in the dark. Second, the visible light was illuminated from the tungsten lamp to the solution under the potentiostatic conditions. Third, the methylium ion in bulk solution absorbed the light and was in the excited state, whereas the radical could not absorb the visible light. Fourth, an electron on the radical was transferred to the excited methylium ion to reproduce the methylium ion at the electrode surface. Fifth, the reproduced methylium ion was again reduced at the electrode surface to generate the photocurrent. This mechanism is, however, only a working hypothesis at the present stage.

similar relationships were observed for the other triarylmethylium salts. These results suggest that the methylium-methyl radical redox couple plays some roles in the generation of cathodic photocurrents. The electronic spectrum of $\Phi^{\mathrm{b}}{ }_{3} \mathrm{C}^{+}$in 1,2-dichloroethane showed a strong band with $\lambda_{\max }$ at $524 \mathrm{~nm}$, while the spectrum of the independently synthesized tris(2,6-dimethoxyphenyl) methyl radical in 1,2-dichloroethane showed a new band at $370 \mathrm{~nm}$ instead of the disappearance of the $524 \mathrm{~nm}$ absorption. ${ }^{4}$ That is, the electronic spectrum of the radicals did not show a strong band in the visible region. So, the direct participation of these radicals formed during the electrolysis ${ }^{4)}$ in the dark seems to be difficult in the generation of cathodic photocurrents. In addition, appearance of the induction period in the generation of photore- 
sponse cannot be explained if the cathodic photocurrent was simply generated by the excitation of the radicals.

The value of the observed photocurrent by these salts was proportional to the concentration of the salts up to 5 $\mathrm{mM}$, and to the illuminance of the incident light up to $10,000 \mathrm{~lx}$.

The mechanism for the generation of photocurrent is presumably proposed (Fig. 3), although the further detailed discussion is difficult at the present stage. However, a consideration of the subsequent electron transfer between the excited triarylmethylium salts and triarylmethyl radicals formed at the electrode surface in the dark seems to be indispensable in order to elucidate the appearance of the induction period. Based on these findings, some attempts such as a measurement of photocurrent action spectrum are in progress.

\section{References}

1) M. Iwaki, S. Kumazaki, K. Yoshihara, T. Erabi, and S. Itoh, J. Phys. Chem., 100, 10802 (1996).

2) M. Wada, H. Mishima, T. Watanabe, S. Natsume, H. Konishi, S. Hayase, and T. Erabi, J. Chem. Soc., Chem. Commun., 1993, 1462; M. Wada, H. Mishima, T. Watan- abe, S. Natsume, H. Konishi, K. Kirishima, S. Hayase, and T. Erabi, Bull. Chem. Soc. Jpn., 68, 243 (1995); M. Wada, T. Watanabe, S. Natsume, H. Mishima, K. Kirishima, and T. Erabi, Bull. Chem. Soc. Jpn., 68, 3233 (1995); M. Wada, H. Konishi, K. Kirishima, H. Takeuchi, S. Natsume, and T. Erabi, Bull. Chem. Soc. Jpn ., 70, 2737 (1997); M. Wada, H. Konishi, T. Kai, H. Takeuchi, S. Natsume, and T. Erabi, Bull. Chem. Soc. Jpn., 71, 1667 (1998); S. Natsurne, H. Kurihara, T. Yamaguchi, T. Erabi, and M. Wada, J. Organomet. Chem., 574, 86 (1999).

3) M. Asahara, S. Natsume, H. Kurihara, T. Yamaguchi, T. Erabi, and M. Wada, J. Organomet. Chem., 601, 246 (2000).

4) T. Erabi, T. Ohtsuki, E. Osaki, N. Tomita, M. Asahara, and M. Wada, Bull. Chem. Soc. Jpn., 73, 2237 (2000).

5) For example, B. O'Regan and M. Grätzel, Nature, 353, 737 (1991); Y. Nishimura, H. Sakuragi, and K. Tokumaru, Bull. Chem. Soc. Jpn., 65, 2887 (1992); K. Uehara and A. Maekawa, J. Appl. Polymer Sci., 48, 2207 (1993); C. Nasr, D. Liu, S. Hotchandani, and P. V. Kamat, J. Phys. Chem., 100, 11054 (1996); K. Sayama, M. Sugino, H. Sugihara, Y. Abe, and H. Arakawa, Chem. Lett., 1998, 753; K. Hara, T. Horiguchi, T. Kinoshita, K. Sayama, H. Sugihara, and H. Arakawa, Chem. Lett., 2000, 316. 